\title{
EXTENDED WORKING LIVES? THE MEANING OF WORKING TO OLDER UNIVERSITY WORKERS IN AUSTRALIA
}

\section{Introduction}

Australia's population and workforce are ageing. The reasons for an ageing population include the post World War II baby boom and low birth rates in subsequent generations. Combined with healthier lifestyles, advances in medical science and the subsequent increase in longevity, this means there are more older Australians than ever before and this trend will continue for several decades (Department of the Treasury, 2004). According to the Productivity Commission (2005), workforce demographics are also affected by ageing, with Australia's workforce ageing faster than its population, resulting in Australian organisations likely needing to employ more older workers in the near future to meet predicted shortfalls of skilled workers.

Although there have been studies examining the retirement decision (Gustman and Steinmeier, 1994, Hansson, DeKoekkoek, Neece, and Patterson., 1997, Patrickson and Clarke, 2001, Phillipson, 2004, Rosenman and McDonald, 1995), older workers’ intentions to continue working remains under-researched. Therefore, the aim of this research was to explore the meaning of working to older workers to better understand whether and why they might want to continue working. Based on an equal sample of both male and female participants, all aged at least 50 years of age, this study explored what it is about working that makes some people want to continue working beyond the traditional age of retirement, while others wish to stop. There are clear implications for individuals, organisations and public policy emanating from an extension to working lives of older workers.

\section{Literature}

\subsection{Extended working lives}


There is a growing debate within Australia about its ageing workforce. The Australian Government (for example, House of Representatives Standing Committee on Health and Ageing, 2005) and its various economic policy advice providers (such as Department of the Treasury, 2004; Productivity Commission, 2005) have generally agreed there will be some negative consequences for the workforce caused by the ageing population, including a labour shortfall of skilled workers. Some academics have also predicted a workforce shortfall (Hartmann, 1998, Henry, 2003, Kendig and Duckett, 2001, Patrickson, 2003). Most government, researchers and interest groups agree that the most desirable strategy to address such a shortfall is increasing the participation of older people in the workforce, and especially extending the working lives of older workers (Department of the Treasury, 2004, Encel, 2003, House of Representatives Standing Committee on Health and Ageing, 2005, Keating, 2004, Patrickson, 2003, Productivity Commission, 2005, RedayMulvey and Taylor, 1996, Sheen, 1999, Sheen, 2000, Sheen, 2001). However, the literature does not explain why individuals make the employment choices they do - to continue working until later in life, or retire early.

\subsection{The meaning of working}

For the individual older worker, the meaning of working is likely based on different experiences, desires, situational factors and personal circumstances. Such individual variation has not been accounted for in either public policy or organisational strategy. Some older workers may value working very highly, finding high levels of meaning in working, and aspiring to extend their working life beyond the traditional age of retirement. In contrast, there may be others for whom working has little meaning, and such workers may be looking forward to the day they leave the pressures or boredom of working. There have been changes in the meanings of working over time (Inglehart, 1997) and the meanings of working 
are culturally bound (Meaning of Working International Research Team [MOWIRT], 1987). According to Ruiz Quintanilla (1991: 85):

Work meanings are values, beliefs, and expectations that individuals hold. Work meanings function as a kind of reference framework for action through holding individual beliefs on what outcomes should be expected and desired from work (work goals), what one has to give or wants to give in the work situation (social norms about working) to achieve those outcomes, and to what degree one identifies with work (the importance the domain has for one’s self image).

According to Morse and Weiss (1955), a person's age is related to changes to the meaning of working on several bases, including job preferences. MOWIRT (1987: 162) found USA work meanings included: "if you get money for it; it adds value to something; if it belongs to your task; if you do it to contribute to society; if you get a feeling of belonging; if it is mentally strenuous; if you do it at a certain time; and if others profit by it”. The meaning of working is also related to levels of skill and education (Friedmann and Havighurst, 1977), work centrality (MOWIRT, 1987), birth cohort and associated socialisation, and work commitment (Loscocco and Kalleberg, 1988). However, there is a gap in the older worker literature about any link between the meaning of working and the intention to continue working.

\subsection{The intention to continue working}

MOWIRT (1987) found a relationship between age and the desire to continue to working, where the importance of working tended to increase with a person's age. Older workers for whom working is not important, who do not enjoy the type of job that they do, and who have strong family ties, were the most likely to want to stop working, argued Harpaz (2002). Wolcott (1998) found more higher educated, professional or managerial older workers continued working than those with less education. According to O’Brien 
(1986), the opportunity for more control and variety available in jobs was important, while Gee and Baillie (1999) found when people felt they had personal control over their destiny, it was a positive influence on continuing to work.

However, there has been little research looking at the combined areas of the meaning of work, the extension to working lives and age; even less using qualitative research methods and less still within the Australian context. The meaning of working to older workers, and why they choose to continue working or not, continues to be under-researched. The aim of this study therefore was to investigate the meaning of working to individual older workers, and explore their intentions to continue working. The research questions were: What is the meaning of working to individual older workers? and How does their meaning of working influence older workers' intentions to continue working? This paper seeks to address these questions through the findings of a study of older workers within a public sector university in Australia.

\section{The research study}

A qualitative research approach was chosen because of the: "concern with meanings and the way people understand things, ... as well as a concern with patterns of behaviour” (Denscombe, 1998: 207). As in other qualitative research: "the researcher typically conducts 20-30 interviews ... to collect data to saturate the categories”, using a "zigzag” process to "gather data, analyze the data, back to the field to gather more information, analyze the data, and so forth” (Cresswell, 1998, p. 57). The research consisted of in-depth semi-structured exploratory interviews with 30 employees and focussed on the experiences, perceptions and understandings of older individuals about the meaning of working and their future working intentions. According to Denzin and Lincoln (2005), semi-structured interviews suit situations where the interviewer is somewhat directive, providing consistency of coverage 
between participants, yet allowing for greater depth than can be achieved with other interview types. On average, the interviews lasted 96 minutes (70 to 135 minutes), were conducted in mutually convenient places and were tape-recorded with the prior consent of each participant. To aid the validity of the research, a hard copy of their interview transcript was sent to each participant for review and feedback, then returned to the researcher for data analysis.

Data was sought in response to questions about participants' meanings of working, their intentions to continue working and working past the age of 65 years (the traditional age of retirement in Australia). This enabled consideration of the various meanings older people have in paid working as they approach retirement and after they have retired, and to identify the sorts of factors that influence their plans to remain working. Data analysis was undertaken by identifying themes or "patterns, processes, commonalities and differences" (Miles and Huberman, 1994: 9). Thematic analysis was completed to find the dominant and less dominant themes, where themes were understood to be: "the manifest generalised statements by informants about beliefs, attitudes, values or sentiments” (Luborsky, 1994: 195). Specialist qualitative research software (NVivo 6.0) was chosen to add to the reliability of the analysis, as rigorous and systematic data processing takes place with its use and data analysis procedures are transparent.

A single organisation (an Australian public sector university) was selected as the context for the study with the benefits of organisational culture, strategic management direction and human resource management policies likely to be similar across the whole organisation. Additionally, as a large organisation, and arguably a microcosm of society, the university has a diverse range of employees in terms of age, job types, levels, skills, experience and education.

\subsection{Participants in the research}


Thirty participants formed the research sample (see Table 1) and were selected using the purposeful sampling technique (Creswell, 1998) by which participants are chosen to ensure representation of differences in the population. Participants of both genders (15 males; 15 females) were therefore selected for their differing ages (but aged at least 50 years), employment histories, location, employment levels, and employment type (15 academic staff; 15 general-administrative staff; blue collar, white collar and professional). The snowballing sampling technique (Minichiello, Aroni, Timewell, and Alexander, 1995) was also used to find some working retiree participants, where participants were asked if they knew of anybody who had retired but was now working for the organisation, and who might be willing to participate. The number of participants was determined by the data emerging. Once the data began being repeated, the point of "saturation" was reached (at thirty participants) and then no more participants were sought (Cresswell, 1998: 57). Six participants had retired and returned to work. The age of 50 years or over was chosen as being representative of those people close to a decision about whether to continue working, as most older workers are retiring earlier than 65 years of age (Department of the Treasury, 2004) and well before the traditional age of retirement at 65 years (Australian Bureau of Statistics, 1998). The average age of retirement from full-time work in Australia was 48 years - 58 for males and 41 for females (Australian Bureau of Statistics, 1998). The average age of all participants in this study was 60.4 years, (60.5 years for males and 60.3 years for females; 61.6 years for academic staff and 59.2 years for general staff).

\section{TABLE 1 Here}

\section{Findings}


To obtain data about the meaning of working to older Australians, participants were asked questions about what working meant to them, how important it was in their lives, what they liked and disliked about working and their intentions to continue working. Seven dominant themes surfaced as a result of data analysis of the interview responses: (i) working is important to older workers; (ii) "family" is more important than "working"; (iii) there is a relationship between the meaning of working and the intention to continue working; (iv) working means satisfaction, challenge and/or achievement; (v) working means helping or seeing others grow and develop; (vi) job type influences the meaning of working; and (vii) autonomy, flexibility and variety are desirable aspects of working. Each dominant theme represents the most similarities in participants' experiences or comments and is presented below with representative comments from participants. The names of participants have been changed to pseudonyms.

\section{(i) Working is important to older workers}

In response to questions about the meaning of working to older individuals, the most dominant theme arising from the data was that working is important. Such importance was explored by seeking ratings $(7=$ one of the most important things in my life; $1=$ one of the least important things in my life) of how important working was in their overall lives. The majority (22 of 30) of participants responded that working was one of the "most important" or "more important" things in their lives, with five academic staff responding at the highest level. The average rating was 5.8 out of 7 . Not one participant rated working as being "least important”. On average, academic participants (6.4 out of 7) rated the importance of working higher than the general staff participants (5.18 out of 7).

Some participants talked about working in terms of how central it was to their lives; others remarked how working made them feel about themselves. For example, Gillian (aged 64, general staff) commented: 
Work means a great deal to me. It's been the centre of my life for a long time... It means independence. It means usefulness. It means that sense of being valued.

For others, such as Ashley (aged 59, academic staff), working was reported in terms of how central it is:

Work is everything. So that's why I can say work is number one, because it is very central and it is an expression of my whole being.

Working was important to most of the participants, however for the majority (particularly the general staff), other things were at least, if not more, important as reported next.

\section{(ii) "Family" is more important than "working"}

Participants were each asked to rank seven choices in importance in their life community, family, friends, hobbies, leisure, spiritual development and working (MOWIRT, 1987). The majority (21 of 30) of participants rated "family" first. Notably, all nine of the female general staff ranked "family" as the most important, while the majority (4 of 6) of the male general staff also ranked "family" first. Of the academic staff, "family” was ranked first by just over half (8 of 15), with more males (6 of 9) than females (2 of 6) ranking it first. By comparison, "working” was ranked first by a third (5 of 15) of the academic staff, compared with a minority (1 of 15$)$ of the general staff participants. While working was perceived as important in their overall lives, as reported previously, most older workers ranked "family" higher than they ranked "working” in relative importance to the other five choices.

(iii) There is a relationship between the meaning of working and the intention to continue working

Most of those participants who rated "working” as important or very important and found meaning in working wanted to continue working, and past the age of 65 years. Most 
of those who rated "working” as less important, especially those who rated "family" first, and who reported finding less meaning in working wanted to stop working. More (12 of 15) general staff wanted to stop working early than did academic staff (3 of 15). Comments of participants wanting to stop working early included: "I am counting the days till I can afford to leave"; "I want to spend more time with my partner"; and "it's time for me to have some time for myself". The majority (12 of 15) of academic staff wanted to continue, or had continued, working past the age of 65 . These academic staff commented that either they hoped never to retire, or they were not ready to stop working "for years", including comments such as: "I want to work until I die”, “I can't see an end to my working” and “why would I retire when I'm already doing all the things I would do in retirement?”. In comparison to the academic staff, the general staff were more likely to comment that they were keen to stop working as soon as they were financially able, including: "if I retire at the age of 62 I will have enough saved to last until I turn 65 and then I can get the (age) pension", "I have worked from the age of 14 and I think that's long enough", and "I want to get on with the rest of my life”.

Those participants who reported finding more meaning in and importance of working also wished to continue working, while the opposite relationship also held. There appeared to be a positive link between the meaning of working and wanting to continue working.

\section{(iv) Working means satisfaction, challenge and/or achievement}

Another theme that emerged in response to the interview questions was that older workers enjoyed a variety of aspects of working, including have a "great love" for working, being able to exercise their talents, that there was "no need to run away to do other things", not being able to separate the concept of working from the enjoyment gained from it, the intellectual stimulation, and the monetary reward. Only one general staff participant commented that he disliked working, adding that he was only there for the money. However, 
the most frequent comments concerned working as meaning satisfaction, challenge and/or achievement. Gina (aged 64, general staff) represented others' views when she noted:

What I like about this most is the challenge. The sense of achievement when you've achieved what you set out to do ...you enjoy some jobs more than others, but in fact I don't think I've ever had a job that I didn't get some satisfaction from.

Ashley (aged 59, academic staff) also commented on working being satisfying and of meaning in his life:

It (working) has to be meaningful and satisfying. I don't know how else to explain it apart from job satisfaction. It's fulfilling.

Participants (both academic and general staff) found a variety of meanings of working but the majority were related to the satisfaction, challenge, and achievement.

\section{(v) Working means helping or seeing others grow and develop}

When asked to further explain or provide an example of how their perceptions of satisfaction, challenge or achievement were reached, many (10 academic staff; 3 general staff) participants observed that one of the key meanings of working for them was being able to help or see other people grow and learn. For example, Greg (aged 56, general staff) said:

I really felt, without wanting to boast, that I had made a big contribution. I felt like I had changed their lives. That's what it's all about.

Mary (aged 69, academic staff) also found watching others grow and learn to be immensely satisfying:

The meaning of working for me is watching people grow and seeing the improvement. That's why I stay here.

Both academic and general staff reported such meanings and rewards from working. In their jobs, academic staff teach students and often have access on a one-to-one basis to students, and thus may have the opportunity to become involved with students at an individual level. The general staff identified satisfaction and rewards from helping other staff to grow and learn, as well as the occasional student when dealing with students was part of their work. 


\section{(vi) Job type influences the meaning of working}

In response to questions about the meaning of working, there appeared to be a difference in participants' meanings based on employment category (or job type). As mentioned previously, academics generally found working to be more important than did general staff. Additionally, in relation to the other six aspects in life, academic staff ranked "working" higher (with an average of 5.9 out of 7) than did general staff (4.67). Female academic staff ranked "working” highest (6.0) and female general staff (4.33) ranked it lowest relative to the other choices. It appears that the type of job or category of employment influences the meaning of working, with academic staff on average rating "working" as more important than the general staff, while general staff on average ranked "family" above "working” and the other five choices.

\section{(vii) Autonomy, flexibility and variety are desirable aspects of working}

Participants' perceptions of nine aspects of working were sought, asking them to rank in order of important: (i) working with other people; (ii) opportunity for promotion; (iii) working conditions; (iv) working hours; (v) variety; (vi) job security; (vii) match between job and abilities; (viii) pay; and (ix) autonomy (MOWIRT, 1987). Across all participants, "autonomy" was the most frequently (12 of 30) rated "most important" working characteristic. Participants' explanations for the high rating included control over timetables, work content, lack of reporting to supervisors and the like. For example, Sue (aged 53, general staff) commented:

I have to work out what I have to do next - so I like that part where you've not got someone telling you exactly when you're going to do something next.

Adam (aged 62, academic staff) explained:

I don't feel that I've had a boss, and of course there are people that you are accountable to, obviously, ... and of course you're responsible to your students, but 
you don't feel like you're in a boss situation with them, nor do you feel there is anyone looking over your shoulder telling you how to do the job.

Several participants also mentioned variety as a key factor in the meaning of working for them. "Variety" was the second most frequently (4 of 30) rated "most important" work characteristic. Some participants talked about "being bored" if they were not given a variety of things to do, while others liked not knowing what they would be doing when they arrived at work on any particular day. For example, Graham (aged 58, general staff) commented on enjoying the day-to-day variety:

I'm quite happy because it's different. Different jobs every day. I can get 10 or 12 jobs every day to do. It's good. Variation. I couldn't be doing the same thing.

Another aspect of working - flexibility - was not part of the MOWIRT (1987) research, and therefore was not listed as one of the choices in the ranking exercise in this study. However, the majority (21 of 30) of participants commented during interview discussions that "flexibility" at work was desirable and a positive influence on their intentions to continue working. Specifically, participants mentioned flexibility in choosing how to complete their tasks, and flexibility in their working arrangements. In general, academic staff commented they had a high level of autonomy and variety, as well as flexibility at work. In contrast, general staff reported having less autonomy generally, but particularly concerning attendance at work, and less flexible working hours and working arrangements than the academic staff. To achieve the desired level of autonomy and flexibility, some general staff commented they felt they needed to retire from work altogether. Academic participants did not report the same perception. As one participant commented: “academics don't need to retire (to have flexibility and autonomy)”.

\section{Discussion}


Some of the findings from this study support previous research literature, namely: most workers find importance and meaning in working (MOWIRT, 1987); the meaning of working is about satisfaction, challenge and achievement (Harpaz, 2002, Meilaender, 2000); autonomy and variety at work are important (Gee and Baillee, 1999, O’Brien, 1996); and job type influences the intention to continue working (Rosenman and McDonald, 1995). However, the previous research was not about older workers’ intentions to continue working, nor conducted in an Australian context (except Rosenman and McDonald, 1995). Other findings have not been previously reported in the literature, namely: 'family' is more important than 'working'; there is a relationship between the meaning of working and the intention to continue working; the work meaning of helping/watching others develop; and flexibility is a desirable aspect of working and an influence on older workers' intentions to continue working.

The most dominant finding, that working is important to older workers, supports previous research (for example, MOWIRT, 1978), but understanding why working is important to older workers is new knowledge. The meanings of working to older workers reported in this paper provide such an understanding, including the important role of the family, the satisfaction, challenge and achievement of working, helping others grow/develop, and the desires for autonomy, flexibility and variety. Additionally, the relationship between such meanings of working and older workers' intentions to continue working has not been reported previously, and such knowledge could be important in assisting organisations and HRM to retain valued older workers.

The differences between the two employment categories of staff (academic and general-administrative) in their meanings of working and related intention to continue working support the argument that highly educated and skilled workers are less likely to retire (Friedmann and Havighurst, 1977, Wolcott, 1998). However, their intention to 
continue working could also be related to job type, as found by Rosenman and McDonald (1995) and supported by the findings in this study. Additionally, the findings from this study suggest that autonomy, flexibility and variety are three characteristics of job type partially influencing the meaning of working and the intention to continue working. While MOWIRT (1987) argued autonomy and variety were two aspects of the meaning of working, their research did not explain any influences on the intention to continue working. Similarly, research by Gee and Baillee (1999) and O’Brien (1996) is supported in terms of the importance of autonomy and variety at work. Further, Blekesaune and Solem (2005) found early retirement was related to low levels of autonomy in job tasks. However, the additional role of flexibility has not been identified previously; yet flexibility appears to be an important factor influencing older workers’ meaning of working and intention to continue working. Further research into the work aspect of flexibility could be worthwhile, as the drive for individual work-life balance appears more important to today’s workers (Noon and Blyton, 2002). From this finding, enabling greater amounts of autonomy, flexibility and variety at work could improve the meaning of working to older workers, leading to extended working lives and thereby assisting to meet the predicted labour shortfall. Hence, there are implications for organisations and HRM concerning job design, job enrichment and other management initiatives to better meet older workers' desires for autonomy, flexibility and variety in their work.

Another key finding was that "family" is very important to older workers. Family considerations that may influence the meaning of working and working intentions of older people typically include the intrinsic rewards gained from spending time with family, care responsibilities and obligations, and economic considerations such as educating children/grandchildren. Szinovacz, DeViney and Davey (2001) found those workers with strong family relationship ties were more likely to retire than those with no such relationship 
ties. The findings in this study supported that literature, where those who rated "family" first were also those who did not want to continue working. However, the majority of older workers ranked "family" higher than "working", perhaps suggesting that ageing makes family ties stronger. Older workers may want to spend the time while healthy to enjoy their families, yet for many, working remains a priority. Of significance are the possible implications of this finding to retention strategies and the need for more flexible working arrangements to enable older workers to meet both family and working needs.

Overall, those who reported working as more important and found greater meaning in working were more likely to want to continue working, and past the age of 65, than those who found less meaning and importance in working. The suggestion of such a relationship between the meaning of working and the intention to continue working may assist organisations and HRM to design staffing strategies to increase retention rates and extend working lives based on enabling older workers to find greater meaning in working. A deeper understanding of the meaning of working, combined with the three desirable job characteristics mentioned above, could be used to better assess the intentions of particular older workers to continue working.

Another finding, not previously reported in the literature - the meaning of working includes helping and watching others grow and develop - may be partly explained because the participants were all employed within a university setting, and may have chosen such an organisation in the expectation that they would find such work meaning there. That is, such a meaning of working may not be generalisable across other occupations and industries. However, this finding adds to knowledge about the meaning of working and the intention to continue working, assisting organisations and HRM to effectively manage an ageing workforce, particularly within the university sector. 
The differences in the meaning of working and the intention to continue working between the literature and the findings in this study may be partly explained because the participants in this study were exclusively older full-time workers, were employed within one organisation and one industry and that organisation was an Australian university. Such differences may point to the meanings of working of older workers being different from people of other ages, occupations, industries, and those working causally or part-time.

\section{Conclusions}

Key findings from the research suggest that despite the Australian Government's attempts to encourage older workers to continue working later in life, many of the older workers did not want to continue working. Rather, they wanted to stop working well before the traditional retirement age of 65 years. Those who rated working as very important in their lives, could meet family needs while working, found satisfaction, challenge or achievement from working, had higher levels of autonomy, flexibility and variety at work and could help or see others grow and develop, were more likely to want to continue working, and for most, past the age of 65 years. In contrast, those who rated working as less important, were less able to meet family needs while working, found less satisfaction, challenge or achievement from working, had lower levels of autonomy, flexibility and variety at work and had less opportunity to help or see others grow and develop, were more likely to want to stop working, some as soon as they estimated they could afford to.

The generalisability of the findings is limited as the sample size was small, employees were within a single organisation, industry and country, all were working full-time and all were aged 50 years or older. Additionally, they worked within a university, and therefore may have unique intrinsic motivating factors (for example, freedom, intellectual contribution or access, and lifelong learning and its associated environment). Finally, with only one 
trained coder interpreting the data, there was no inter-rater reliability to add to validity. Further research in broader contexts, in other locations and with more than one coder could therefore be worthwhile. Given the similar ageing populations in most other industrialised countries, it may be that the findings from this study could be used as indicators for further research in those countries.

Notwithstanding these limitations, a greater understanding of older workers’ meaning of working and intention to continue working, based on an individual level of analysis, has resulted from this research. The relationship between older workers' meanings of working and their intentions to continue working could be an important addition to HRM knowledge, particularly in relation to increasing retention rates of valued older workers. For example, the roles of family, satisfaction, challenge and achievement at work, and the opportunity to help others grow or develop could be used as indicators of older workers' intentions to continue working. Further, three characteristics of jobs - autonomy, flexibility and variety could be integrated into job design to better attract older workers to remain in or return to the workforce. From the findings in this study, by designing jobs, supervision and working arrangements to enable older workers to find more meaning in working, and by maximising certain characteristics of their jobs, older workers are more likely to continue working. Public policy, organisations and HRM could use the knowledge from this study to develop better strategies and policies to increase the likelihood of older workers extending their working lives, and address the predicted looming labour shortfall in Australia. 


\section{REFERENCES}

Australian Bureau of Statistics (1998) 'Retirement and retirement intentions', Australian Bureau of Statistics: Canberra.

Blekesaune, M. and Solem, P. E. (2005) 'Working conditions and early retirement: A prospective study of retirement behavior', Research on Aging, Vol. 27, No. 1, pp. 330.

Denzin, N. K., \& Lincoln, Y. S. (2005). Handbook of qualitative research (3rd ed.). Thousand Oaks: Sage Publications.

Department of the Treasury (2004) Australia's Demographic Challenges, Department of the Treasury: Canberra.

Encel, S. (2003) Age can work: The case for older Australians staying in the workforce, Australian Council of Trade Unions and Business Council of Australia: Sydney.

Friedmann, E. A. and Havighurst, R. J. (1977) The meaning of work and retirement, Arno Press: New York.

Gee, S. and Baillie, J. (1999) 'Happily ever after? An exploration of retirement expectations', Educational Gerontology, Vol. 25, pp. 109-128.

Gustman, A. L., and Steinmeier, T. L. (1994). 'Retirement analysis, social security and pensions'. NBER Reporter, Vol. Summer, pp. 14 -18.

Hansson, R. O., DeKoekkoek, P. D., Neece, W. M. and Patterson, D. W. (1997) 'Successful aging at work: Annual Review, 1992-1996: The older worker and transitions to retirement', Journal of Vocational Behavior, Vol. 51, pp. 202-233.

Harpaz, I. (2002) 'Expressing a wish to continue or stop working as related to the meaning of work', European Journal of Work and Organizational Psychology, Vol. 11, No. 2, pp. 177-198. 
Hartmann, L. (1998) 'The impact of trends in labour force participation in Australia'. In (Eds, Patrickson, M. and Hartmann, L.), Managing an ageing workforce, Business and Professional Publishing: Warriewood. NSW, pp. 3-25.

Henry, K. (2003) The Intergenerational Report - 18 months on, In, 2004 Conference presentation, November 13.

House of Representatives Standing Committee on Health and Ageing (2005) Future Ageing: Inquiry into long-term strategies to address the ageing of the Australian population over the next 40 years, Parliament of the Commonwealth of Australia: Canberra.

Inglehart, R. (1997) Modernization and postmodernization: Cultural, economic and political change in 43 societies, Princeton University Press: Princeton, New Jersey.

Keating, M. (2004) 'Increasing labour force participation', Australia's ageing population: Fiscal, labour market and social implications, Committee for Economic Development of Australia, pp. 66-74.

Kendig, H. and Duckett, S. (2001) Australian directions in aged care: The generation of policies for generations of older people. Australian Health Policy Institute, University of Sydney. Commissioned Paper Series 2001/05.

Loscocco, K. A. and Kalleberg, A. L. (1988) 'Age and the meaning of work in the United States and Japan', Social Forces, Vol. 67, No. 2, pp. 337-356.

Meilaender, G. C. (2000). Working: Its meaning and limitations. Indiana: University of Notre Dame Press.

Morse, N. L. and Weiss, R. S. (1955) 'The function and meaning of work and the job', American Sociological Review, Vol. 20, pp. 191-198.

Meaning of Working International Research Team (1987) The meaning of working, Academic Press: London.

Noon, M. and Blyton, P. (2002) The realities of work, Palgrave: London. 
O'Brien, G. E. (1986) Psychology of work and unemployment, Wiley: Chichester.

Patrickson, M. (2003) 'Human resource management and the ageing workforce'. In (Eds, Weisner, R. and Millett, B.), Human resource management: Challenges and future directions., Wiley: Brisbane, pp. 33-43.

Patrickson, M., and Clarke, M. (2001). Voluntary redundancy: Its role in stimulating early retirement. Paper presented at the Australian and New Zealand Academy of Management Conference, Auckland.

Phillipson, C. (2004). 'Work and retirement transitions: Changing sociological and social policy contexts’. Social Policy and Society, Vol. 3, No. 2, pp. 155-162.

Productivity Commission (2005) Economic implications of an ageing Australia: Research report, Australian Government Productivity Commission: Canberra.

Reday-Mulvey, G. and Taylor, P. (1996) 'Why working lives must be extended', People Management, Vol. 2, No. 10, pp. 24-27.

Rosenman, L. and McDonald, S. (1995) 'How should universities respond to the abolition of compulsory retirement?' Australian Universities Review, Vol. 38, No. 1, pp. 63-66.

Ruiz Quintanilla, S. A. (1991) 'Introduction: The meaning of work', European Work and Organizational Psychologist, Vol. 1, No. 2/3, pp. 81-89.

Sheen, V. (1999) Older Australians: Working for the future, Council on the Ageing: Melbourne.

Sheen, V. (2000) Older Australians: A working future ? Council on the Ageing and Committee for Economic Development of Australia: Melbourne.

Sheen, V. (2001) 'The economics of the ageing population: The role of mature age employment', In Committee for Economic Development of Australia Seminar, Melbourne. 
Szinovacz, M. E., DeViney, S. and Davey, A. (2001) 'Influences of family obligations and relationships on retirement: Variations by gender, race, and marital status', Journal of Gerontology: Social Sciences, Vol. 56B, No. 1, pp. S20-S27.

Wolcott, I. (1998) Families in later life: Dimensions of retirement, Australian Institute of Family Studies: Melbourne.

Table 1: Participant categories and average ages

\begin{tabular}{|l|c|c|c|c|}
\hline & ACADEMIC & GENERAL & AGE (in & TOTAL \\
\hline MALES & 9 & STAFF & years) & \\
\hline Age Range (years) & $53-67$ & $56-61$ & $53-67$ & \\
\hline Average age (years) & 60.9 & 60 & 60.5 & \\
\hline FEMALES & 6 & 9 & & 15 \\
\hline Age Range (years) & $54-69$ & $52-64$ & $52-69$ & \\
\hline Average age (years) & 62.7 & 58.7 & 60.3 & \\
\hline TOTAL & 15 & 15 & & \\
\hline Average Age of all & & 59.2 & 60.4 & \\
participants & 61.6 & & & \\
\hline
\end{tabular}

